\author{
Gambaran Pelayanan Informasi Obat Pada Pasien \\ Hipertensi di Apotek Abifayruz Klinik FDC \\ (Family Doctor Clinic) Makassar \\ Megawati ${ }^{1}$, Geby Delin Priska ${ }^{2}$ \\ Jurusan Farmasi Politeknik Sandi Karsa Makassar ${ }^{1,2}$
}

\begin{abstract}
ABSTRAK
Telah dilakukan penelitian mengenai Gambaran Pelayanan Informasi Obat Pada Pasien Hipertensi Di Apotek Abifayruz Klinik Fdc (Family Doctor Clinic) Makassar. Tujuan penelitian ini adalah untuk mengetahui gambaran pelayanan informasi obat pada pasien hipertensi Di Apotek Abifayruz Klinik Fdc (Family Doctor Clinic) Makassar. Metode penelitian ini bersifat deskriptif yaitu data diperoleh dengan mengumpulkan hasil jawaban dari kuesioner kemudian ditabulasi, diskoring, dipersentasekan dan dibuat tabel. Berdasarkan hasil penelitian disimpulkan bahwa pasien hipertensi yang menerima pelayanan informasi obat di Apotek Abifayruz Klinik FDC merasa puas dengan persentase $74,62 \%$.
\end{abstract}

Kata Kunci: Pelayanan Informasi Obat, Hipertensi

Coresponden Author:

Megawati

apt.megawatisyafrin@gmail.com 


\title{
Description of Drug Information Services for Hypertension Patients at Drugstore of Abifayrus Clinic FDC \\ (Family Doctor Clinic) Makassar
}

\author{
Megawati ${ }^{1}$, Geby Delin Priska ${ }^{2}$ \\ Jurusan Farmasi Politeknik Sandi Karsa Makassar ${ }^{1,2}$
}

\begin{abstract}
The research has been done about the description of drug information cervices in hypertensive patients at pharmacies of Abifayruz klinik fdc (family doctor clinic) Makassar.The aim of this research is to know the description of drug information services in hypertensive patients at pharmacies of Abifayruz klinik fdc (family doctor clinic) Makassar. The method of this research is descriptive namely the data obtained by collecting the answers from questionnaires then make tabulation and scoring, and then it will be presented by making a list. Based on the research it can be inferred that hypertensive patient who accepts drug information cervices at pharmacies of Abifayruz klinik fdc, got satisfaction with percentage $74,62 \%$.
\end{abstract}

Keywords: Drugs Information Services, Hipertension 


\section{PENDAHULUAN}

\section{A. Latar Belakang}

Hipertensi merupakan suatu keadaan meningkatnya tekanan darah sistolik lebih dari sama dengan $140 \mathrm{mmHg}$ dan diastolik lebih dari sama dengan $90 \mathrm{mmHg}$. Hipertensi dapat diklasifikasikan menjadi dua jenis yaitu hipertensi primer atau esensial yang penyebabnya tidak diketahui dan hipertensi sekunder yang dapat disebabkan oleh penyakit ginjal, penyakit endokrin, penyakit jantung, dan gangguan anak ginjal (adrenal). Hipertensi memiliki beberapa faktor risiko yaitu umur, jenis kelamin dan suku, faktor genetik serta faktor lingkungan yang meliputi obesitas, stres, konsumsi garam, merokok, konsumsi alkohol, dan sebagainya. Beberapa faktor yang mungkin berpengaruh terhadap timbulnya hipertensi biasanya tidak berdiri sendiri, tetapi secara bersama-sama (Yonata and Pratama, 2016).

Menurut data WHO, di seluruh dunia, sekitar 972 juta orang atau 26,4\% penghuni bumi mengidap hipertensi, angka ini kemungkinan akan meningkat menjadi $29,2 \%$ di tahun 2025 . Dari 972 juta pengidap hipertensi, 333 juta berada di negara maju dan 639 sisanya berada di negara berkembang, termasuk Indonesia. Berdasarkan data Departemen Kesehatan Indonesia, prevalensi hipertensi di Indonesia mencapai $31,7 \%$ dan populasi pada usia 18 tahun ke atas. Sekitar $60 \%$ penderita hipertensi berakhir pada stroke. Sedangkan sisanya mengakibatkan penyakit jantung, gagal ginjal, dan kebutaan (Yonata and Pratama, 2016).

Standar Pelayanan Kefarmasian merupakan pedoman bagi tenaga kefarmasian dalam menyelenggarakan pelayanan kefarmasian. Standar pelayanan kefarmasian di apotek meliputi pengelolaan sediaan farmasi dan pelayanan farmasi klinik. Dalam konteks pelayanan kefarmasian apotek, kepuasan pasien merupakan perasaan senang yang muncul di dalam diri seorang setelah mendapat pelayanan yang diterima atau dialami secara langsung (Yuniar and Handayani, 2016).

Analisis kepuasan pelanggan dilakukan bedasarkan lima dimensi kualitas layanan, yakni responsiveness, reliability, assurance, empathy, dan tangible. Responsiveness (ketanggapan) adalah keinginan petugas membantu pelanggan untuk memberikan pelayanan dengan cepat seperti kecepatan petugas loket melayani pasien, kecepatan pelayanan obat, dan kelengkapan informasi obat yang diberikan kepada pasien. Reliability (kehandalan) adalah kemampuan untuk memberikan pelayanan yang sesuai dengan janji yang ditawarkan. Assurance (jaminan) adalah dimensi kualitas yang berhubungan dengan kompetensi front-linestaff dalam menanamkan rasa percaya dan keyakinan kepada pelanggan, seperti ketersediaan obat di apotek dan seluruh obat yang diresepkan ditanggung oleh BPJS Kesehatan. Empathy (keramahan) dalam pelayanan apotek antara lain keramahan petugas apotek. Tangible (bukti nyata) antara lain keterjangkauan lokasi apotek, kecukupan tempat duduk di ruang tunggu, kebersihan dan kenyamanan ruang tunggu (Yuniar and Handayani, 2016).

Kepuasan pasien dipengaruhi atas dua aspek yakni aspek pelanggan dan aspek pelayanan kesehatan. Aspek pelanggan dipengaruhi oleh umur, jenis kelamin, pendidikan, dan lain-lain. Sedangkan aspek pelayanan kesehatan terdiri dari dua faktor, yaitu aspek medis, seperti tersedianya peralatan yang memadai, dan aspek non medis yang mencakup layanan petugas kesehatan, kenyamaan dan kebersihan ruang tunggu, serta biaya yang murah (Yuniar and Handayani, 2016).

Beberapa penelitian sebelumnya telah menunjukkan hasil yang baik, seperti penelitian dari Asyhari Asyikin di Apotek Sejati Farma tahun 2018, Sukamanto dan Herlinda di RSUP Dr. Wahidin Sudirohusodo Kota Makassar tahun 2017 dan Ira widya, dkk di DEPO IGD RS TK II Pelamonia Makassar tahun 2018. (Asyikin, 2018), (Sukamanto, 2017), (Sari et al., 2018). Meski demikian penelitian-penelitian tersebut tidak lantas mewakili semua pelayanan kesehatan yang ada di Makassar. Masih ditemukan masalah di tempat pelayanan kefarmasian baik apotek, puskesmas, maupun rumah sakit terkait tanggapan yang kurang memuaskan dari pelayanan informasi obat maupun yang dipengaruhi oleh beberapa faktor seperti jumlah petugas yang terbatas, jumlah pasien yang tidak seimbang dengan waktu pelayanan, dan juga berkaitan dengan managemen farmasi (penyimpanan dan ketersediaan obat).

Berdasarkan uraian diatas maka peneliti merasa perlu untuk dilakukan penelitian mengenai Gambaran Pelayanan Informasi Obat Pada Pasien Hipertensi Di Apotek Abifayruz Klinik Fdc (Family Doctor Clinic) Makassar.

\section{B. Rumusan Masalah}

Bagaimana Gambaran Pelayanan Informasi Obat Pada Pasien Hipertensi Di Apotek Abifayruz Klinik Fde (Family Doctor Clinic) Makassar?

\section{Tujuan Penelitian \\ Mengetahui Gambaran Pelayanan Informasi Obat Pada Pasien Hipertensi Di}


Apotek Abifayruz Klinik Fdc (Family Doctor Clinic) Makassar.

\section{Manfaat Penelitian}

1. Untuk bahan masukkan bagi pihak farmasis dalam meningkatkan pelayanan kefarmasian, khususnya pelayanan informasi obat (PIO)

2. Sebagai bahan referensi bagi farmasis untuk memperbaiki dan meningkatkan pelayanan kefarmasian, khususnya pelayanan informasi obat.

3. Sebagai sumber informasi dan referensi untuk penelitian berikutnya dan sebagai data awal dalam penelitian selanjutnya.

\section{METODE PENELITIAN}

\section{A. Jenis Penelitian}

Penelitian ini adalah penelitian yang bersifat deskriptif untuk mengetahui Gambaran Pelayanan Informasi Obat Pada Pasien Hipertensi Di Apotek Abifayruz Klinik Fdc (Family Doctor Clinic) Makassar dengan memberikan data primer kepada pasien melalui lembar kuesioner.

\section{B. Lokasi dan Waktu Penelitian}

Penelitian ini dilaksanakan di Apotek Abifayruz Klinik Fdc (Family Doctor Clinic) Makassar pada bulan Maret tahun 2021.

\section{Populasi dan Sampel}

Populasi dalam penelitian ini adalah semua pasien rawat jalan yang datang berobat dan mengambil obat di Apotek Abifayruz Klinik Fdc (Family Doctor Clinic) Makassar. Besar populasi adalah sebanyak 200 orang.

Sampel dalam penelitian ini adalah pasien rawat jalan yang datang ke Apotek Abifayruz Klinik Fdc (Family Doctor Clinic) Makassar dengan kriteria telah mendapatkan pelayanan informasi obat minimal 2 kali, pendidikan minimal SMP/Sederajat, usia 17-50 tahun dan bersedia untuk mengisi kuesioner.

Adapun besar sampel ditentukan berdasarkan rumus Slovin dengan tingkat kesalahan $10 \%$.

Rumus Slovin yaitu

$$
\mathrm{n}=\frac{\mathrm{N}}{1+N(d)^{2}}
$$

Dimana:

$\mathrm{n}$ : jumlah sampel penelitian

$\mathrm{N}$ : jumlah populasi

d: presisi (ditetapkan 10\% dengan tingkat kepercayaan 95\%)

$\mathrm{n}=\frac{\mathrm{N}}{1+N(d)^{2}}$

$$
\begin{gathered}
\mathrm{n}=\frac{200}{1+200(0,1)^{2}} \\
\mathrm{n}=\frac{200}{1+2} \\
\mathrm{n}=\frac{200}{3} \\
\mathrm{n}=67
\end{gathered}
$$

Jadi sampel yang akan digunakan adalah sebanyak 67 orang.

\section{Desain Penelitian}

1. Pengumpulan Data

Teknik pengumpulan data yang digunakan adalah dengan membagikan kuesioner pada pasien. Data di peroleh dengan mengumpulkan hasil jawaban dari kuesioner tersebut.

2. Pengolahan Data

Teknik yang digunakan dalam pengolahan data adalah berdasarkan data yang berada dilapangan yakni data yang diperoleh dengan mengumpulkan hasil jawaban dari kuesioner tersebut kemudian ditabulasi, diskoring, dipersentasekan dan dibuat dalam bentuk tabel.

Data yang diperoleh kemudian diolah untuk menentukan persentase jawaban responden dengan menggunakan rumus:

Persentase $=\frac{\text { jumlah } \text { poin perolehan }}{\text { skor ideal }} \times 100 \%$

Skor ideal $=$ jumlah responden $\mathrm{x}$ jumlah pertanyaan x skor tertinggi

Data hasil kuesioner tersebut selanjutnya dibuat dalam bentuk tabel, lalu ditentukan tingkat kepuasan pasien sebagai berikut:

a) Pemberian skor

1. Untuk jawaban puas, diberi poin: 3

2. Untuk jawaban cukup puas, diberi poin: 2

3. Untuk jawaban tidak puas, diberi poin: 1

b) Persentase skor $=$ $\frac{\text { jumlah poin perolehan }}{\text { skor ideal }} \times 100 \%$

c) Jawaban yang diperoleh berdasarkan persentase skor dibagi dalam 3 kategori, yaitu:

1. Tidak puas: jika $\%$ jawaban responden $0 \%$ - 33,33\%

2. Cukup puas: jika $\%$ jawaban responden $33,34 \%-66,66 \%$

3. Puas: jika $\%$ jawaban responden $66,67 \%$ $100 \%$

\section{E. Definisi Operasional}


1. Pasien rawat jalan adalah pasien yang datang berobat di klinik puskesmas tanpa menginap dan mendapat pelayanan kefarmasian.

2. Pelayanan informasi obat adalah pemberian informasi obat kepada pasien, antara lain: aturan pakai obat, dosis obat, cara penggunaan obat, kegunaan/khasiat obat, pantangan obat tersebut terhadapat makanan dan minuman tertentu, efek samping obat, lama penggunaan obat dan cara penyimpanan obat.

3. Kamar Obat merupakan tempat tertentu, tempat dilakukannya pekerjaan kefarmasian dan penyaluran kefarmasian, serta perbekalan kesehatan lainnya kepada masyarakat pada Kamar Obat Di Apotek Abifayruz Klinik FDC (Family Doctor Clinik) Makassar.

\section{HASIL DAN PEMBAHASAN}

\section{A. Hasil Penelitian}

Berdasarkan hasil penelitian yang dilakukan terhadap 67 orang responden atau pasien rawat jalan yang merupakan sampel terpilih yang telah mendapat pelayanan informasi obat di Apotek Abifayruz Klinik FDC (Family Doctor Clinik) Makassar pada bulan Maret tahun 2021. Hasil jawaban kuesioner diperoleh selama penelitian berdasarkan item pertanyaan adalah sebagai berikut:

Tabel I. Data Tanggapan Kepuasan Pasien Terhadap Keramahan Petugas Dalam Memberikan Pelayanan Informasi Obat

\begin{tabular}{cccc}
\hline No & Jawaban & Jumlah & Persentase $(\%)$ \\
\hline 1 & Puas & 58 & 86,57 \\
\hline 2 & Cukup Puas & 9 & 13,43 \\
\hline 3 & Tidak Puas & - & - \\
\hline & Jumlah & 67 & 100 \\
\hline
\end{tabular}

Sumber: Data primer 2021

Berdasarkan sumber diatas menunjukkan bahwa 58 orang $(86,57 \%)$ responden menyatakan puas mengenai keramahan petugas dalam memberikan pelayanan informasi obat yang disampaikan kepada responden, 9 orang $(13,43 \%)$ responden menyatakan cukup puas mengenai keramahan petugas dalam memberikan pelayanan informasi obat yang disampaikan kepada responden.

Tabel II. Data Tanggapan Pasien Mengenai Penjelasan Pentugas Tentang \begin{tabular}{ccc}
\multicolumn{2}{l}{ Informasi Pegunaan Obat } & \\
Jawaban & Jumlah & Persentase (\%)
\end{tabular}

\begin{tabular}{cccc}
\hline No & Jawaban & Jumlah & Persentase $(\%)$ \\
\hline 1. & Puas & 51 & 76,11 \\
\hline 2. & Cukup Puas & 16 & 23,89 \\
\hline
\end{tabular}

\begin{tabular}{cccc}
\hline 3. & Tidak Puas & - & 0 \\
\hline & Jumlah & 67 & 100
\end{tabular}

Sumber: Data primer 2021

Berdasarkan tabel diatas menunjukkan bahwa 51 orang $(76,11 \%)$ responden menyatakan puas mengenai penjelasan petugas tentang kegunaan obat yang disampaikan kepada responden, 16 orang $(23,89 \%)$ responden menyatakan cukup puas mengenai penjelasan petugas tentang kegunaan obat yang disampaikan kepada responden.

Tabel III. Data Tanggapan Pasien Mengenai Penjelasan Petugas Tentang Waktu Penggunaan Obat

\begin{tabular}{cccc}
\hline No & Jawaban & Jumlah & Persentase $(\%)$ \\
\hline 1. & Puas & 51 & 76,11 \\
\hline 2. & Cukup Puas & 16 & 23,89 \\
\hline 3. & Tidak Puas & - & 0 \\
\hline & Jumlah & 67 & 100 \\
\hline
\end{tabular}

Sumber: Data primer 2021

Berdasarkan tabel diatas menunjukkan bahwa 51 orang $(76,11 \%)$ responden menyatakan puas mengenai penjelasan petugas tentang waktu penggunaan obat, 16 orang $(23,89 \%)$ responden menyatakan cukup puas mengenai penjelasan petugas tentang waktu penggunaan obat.

Tabel IV. Data Tanggapan Pasien Mengenai Penjelasan Petugas Tentang Efek Samping Obat

\begin{tabular}{cccc}
\hline No & Jawaban & Jumlah & $\begin{array}{c}\text { Persentase } \\
(\%)\end{array}$ \\
\hline 1. & Puas & 45 & 67,16 \\
\hline 2. & Cukup Puas & 20 & 29,85 \\
\hline 3. & Tidak Puas & 2 & 2,99 \\
\hline & Jumlah & 67 & 100 \\
\hline
\end{tabular}

Sumber: Data primer 2021

Berdasarkan tabel diatas menunjukkan bahwa 45 orang $(67,164 \%)$ responden menyatakan puas mengenai penjelasan petugas tentang efek samping obat yang disampaikan, 20 orang $(29,85 \%)$ responden menyatakan cukup puas mengenai penjelasan petugas tentang efek samping obat yang disampaikan, 2 orang $(2,99 \%)$ responden menyatakan tidak puas mengenai penjelasan petugas tentang efek samping obat yang disampaikan.

Tabel V. Data Tanggapan Pasien Mengenai Penjelasan Petugas Tentang Kontra Indikasi Obat.

\begin{tabular}{cccc}
\hline No & Jawaban & Jumlah & Persentase (\%) \\
\hline 1. & Puas & 40 & 59,70 \\
\hline 2. & Cukup Puas & 24 & 35,82 \\
\hline 3. & Tidak Puas & 3 & 4,48 \\
\hline
\end{tabular}


\begin{tabular}{ccc}
\hline Jumlah & 67 & 100 \\
\hline
\end{tabular}

Sumber: Data primer 2021

Berdasarkan tabel diatas menunjukkan bahwa 40 orang $(59,70 \%)$ responden menyatakan puas mengenai penjelasan petugas tentang kontra indikasi obat, 24 orang $(35,82 \%)$ responden menyatakan cukup puas mengenai penjelasan petugas tentang kontra indikasi obat, 3 orang $(4,48 \%)$ responden menyatakan tidak puas mengenai penjelasan petugas tentang kontra indikasi obat.

Tabel VI. Data Tanggapan Pasien Mengenai Kepuasan Pasien Tentang Penjelasan Cara Penyimpanan Obat

\begin{tabular}{cccc}
\hline No & Jawaban & Jumlah & Persentase (\%) \\
\hline 1. & Puas & 55 & 82,08 \\
\hline 2. & Cukup Puas & 11 & 16,42 \\
\hline 3. & Tidak Puas & 1 & 1,50 \\
\hline & Jumlah & 67 & 100
\end{tabular}

Sumber : Data Primer 2021

Berdasarkan tabel diatas menunjukkan bahwa 55 orang $(82,08 \%)$ responden menyatakan puas mengenai penjelasan petugas tentang cara penyimpanan obat, 11 orang $(16,42 \%)$ responden menyatakan cukup puas mengenai penjelasan petugas tentang cara penyimpanan obat, dan 1 orang $(1,50 \%)$ responden menyatakan tidak puas mengenai penjelasan petugas tentang cara penyimpanan obat.

Tabel VII. Data Tanggapan Pasien Mengenai Penjelasan Petugas Tentang Jangka Waktu Penggunaan Obat

\begin{tabular}{cccc}
\hline No & Jawaban & Jumlah & Persentase $(\%)$ \\
\hline 1. & Puas & 50 & 74,62 \\
\hline 2. & Cukup Puas & 16 & 23,88 \\
\hline 3. & Tidak Puas & 1 & 1,50 \\
\hline & Jumlah & 67 & 100
\end{tabular}

Sumber: Data Primer 2021

Berdasarkan tabel diatas menunjukkan bahwa 50 orang $(74,62 \%)$ responden menyatakan puas mengenai penjelasan petugas terhadap jangka waktu penggunaan obat, 16 orang $(23,88 \%)$ responden menyatakan cukup puas mengenai penjelasan petugas terhadap jangka waktu penggunaan obat, 1 orang $(1,50 \%)$ responden menyatakan tidak puas mengenai penjelasan petugas terhadap jangka waktu penggunaan obat.

Tabel VIII. Data Tanggapan Pasien Mengenai Kepuasan Pasien Tentang Kejelasan Penulisan Etiket (Aturan Pakai) Obat.

\begin{tabular}{cccc}
\hline No & Jawaban & Jumlah & Persentase $(\%)$ \\
\hline 1. & Puas & 47 & 70,14 \\
\hline 2. & Cukup puas & 19 & 28,36 \\
\hline 3. & Tidak puas & 1 & 1,50 \\
\hline
\end{tabular}

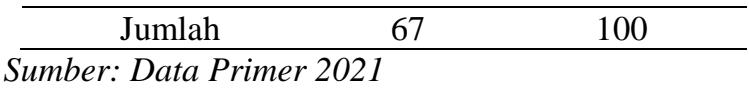

Berdasarkan tabel diatas menunjukkan bahwa 47 orang $(70,14 \%)$ responden menyatakan puas terhadap kejelasan penulisan etiket (aturan pakai) obat oleh petugas, 19 orang $(28,36 \%)$ responden menyatakan cukup puas terhadap kejelasan penulisan etiket (aturan pakai) obat oleh petugas, 1 orang $(1,50 \%)$ responden menyatakan tudak puas terhadap kejelasan penulisan etiket (aturan pakai) obat oleh petugas.

Tabel IX. Data Tanggapan Pasien Mengenai Kecepatan Petugas Dalam Menyiapkan Obat

\begin{tabular}{cccc}
\hline No & Jawaban & Jumlah & Persentase $(\%)$ \\
\hline 1. & Puas & 53 & 79,10 \\
\hline 2. & Cukup Puas & 13 & 19,40 \\
\hline 3. & Tidak Puas & 1 & 1,50 \\
\hline & Jumlah & 67 & 100
\end{tabular}

Sumber: Data Primer 2021

Berdasarkan tabel diatas menunjukan bahwa 53 orang $(79,10 \%)$ responden menyatakan puas mengenai kecepatan petugas dalam menyiapkan obat, 13 orang $(19,40 \%)$ responden menyatakan cukup puas mengenai kecepatan petugas dalam menyiapkan obat, 1 orang $(1,50 \%)$ responden menyatakan tidak puas mengenai kecepatan petugas dalam menyiapkan obat.

Tabel X. Data Skor Hasil Kuesioner

\begin{tabular}{cccc}
\hline No. & Jawaban & Jumlah & Persentase $(\%)$ \\
\hline 1 & Puas & 450 & 74,62 \\
\hline 2 & Cukup puas & 144 & 23,88 \\
\hline 3 & Tidak puas & 9 & 1,50 \\
\hline & Total & 603 & 100 \\
\hline
\end{tabular}

Sumber: Data Primer 2021

\section{B. Pembahasan}

Pelayanan informasi obat merupakan salah satu pekerjaan kefarmasian dalam bidang klinis yang masuk ke dalam ranah pharmaceutical care atau pelayanan farmasi. Kegiatannya meliputih pemberian infomasi seputar obat yang akan diberikan kepada pasien seperti indikasi obat, dosis, waktu penggunaan, efek samping, kontra indikasi, maupun interaksi obat.

Farmasis sendiri dalam menjalankan tugasnya mempunyai tugas yaitu melaksanakan peracikan, pemyerahan, pelayanan, obat/bahan obat atas permintaan dokter, serta pemberian informasi obat dan adapun tugas non teknis seorang farmasis mulai dari pemilihan, perencanaan, pengadaan, penerimaan, penyimpanan, pendistribusian, pengendalian, penghapusan, administrasi dan pelaporan serta 
evaluasi yang diperlukan bagi kegiatan pelayanan.

Penelitian dilakukan dengan memberikan kuesioner kepada pasien yang memenuhi kriteria. Kuesioner berisi 10 pertanyaan mengenai Pelayanan Informasi Obat (PIO). Dari jawaban pada kuesioner ditampilkan dalam bentuk tabel dan diperoleh hasil dengan rentang jawaban dari tidak puas, cukup puas dan puas.

Berdasarkan hasil kuesioner, jawaban responden yang menyatakan kepuasan pasien tentang keramahan petugas dalam memberikan pelayanan informasi obat, penjelasan petugas tentang kegunaan obat, kepuasan pasien mengenai penjelasan petugas tentang waktu penggunaan obat, kepuasan pasien mengenai penjelasan petugas tentang efek samping obat, kepuasan pasien mengenai penjelasan petugas tentang kontra indikasi obat, kepuasan pasien mengenai penjelasan petugas tentang cara penyimpanan obat, kepuasan pasien terhadap jangka waktu penggunaan obat, kepuasan pasien mengenai kejelasan penulisan etiket (aturan pakai) obat, kepuasan pasien mengenai kecepatan petugas dalam menyiapkan obat, maka diperoleh hasil bahwa sebagian besar pasien mereka puas terhadap pelayanan informasi obat mereka peroleh di Apotek Abifayruz Klinik FDC (Family Doctor Clinik) Makassar.

\section{PENUTUP}

\section{A. Kesimpulan}

Berdasarkan data hasil penelitian yang diperoleh yaitu sebanyak $74,62 \%$ pasien merasa puas terhadap pelayanan informasi obat yang diberikan pada saat menerima obat di Apotek Abifayruz Klinik FDC (Family Doctor Clinik) Makassar.

B. Saran

Tetap melakukan evaluasi secara berkala bagi seluruh petugas farmasi di di Apotek Abifayruz Klinik FDC (Family Doctor Clinik) Makassar. Dan dilakukan juga di klinik, puskesmas, maupun Rumah Sakit yang ada di wilayah Makassar.

\section{DAFTAR PUSTAKA}

Asyikin, A., 2018. Studi Implementasi Sistem Penyimpanan Obat Berdasarkan Standar Pelayanan Kefarmasian Di Apotek Sejati Farma Makassar. Media Farmasi 14, 85-90. https://doi.org/10.32382/mf.v14i1.87

Sari, I.W., Fajar, D.R., Rahmawati, R., 2018. Evaluasi Tingkat Kepuasan Pasien
Terhadap Pelayanan Kefarmasian Di Depo Igd Rumah Sakit Tk Ii Pelamonia Makassar. Media Farmasi 14, 78-84. https://doi.org/10.32382/mf.v14i2.599

Sukamanto, H., 2017. Evaluasi Kepuasan Pasien terhadap Pelayanan Kefarmasian di Apotek Rawat Jalan RSUP Dr. Wahidin Sudirohusodo Kota Makassar. Universitas Islam Negeri Alauddin Makassar.

Yonata, A., Pratama, A.S.P., 2016. Hipertensi sebagai Faktor Pencetus Terjadinya Stroke. Jurnal Majority 5, 17-21.

Yuniar, Y., Handayani, R.S., 2016. Kepuasan Pasien Peserta Program Jaminan Kesehatan Nasional terhadap Pelayanan Kefarmasian di Apotek. Jurnal Kefarmasian Indonesia 6, 39-48.

https://doi.org/10.22435/jki.v6i1.5468.39-48 